\title{
GaN-Based High-Output-Power Blue Laser Diodes
}

\author{
Takashi Miyoshi Non-member (Nichia Corporation, takashi.miyoshi.2@nichia.co.jp) \\ Tokuya Kozaki Non-member (Nichia Corporation, tokuya.kozaki@nichia.co.jp) \\ Tomoya Yanamoto Non-member (Nichia Corporation, tomoya.yanamoto@nichia.co.jp) \\ Yasushi Fujimura Non-member (Nichia Corporation, yasushi.fujimura@nichia.co.jp) \\ Shin-ichi Nagahama Non-member (Nichia Corporation, shinichi.nagahama@nichia.co.jp) \\ Takashi Mukai Member (Nichia Corporation, takashi.mukai@nichia.co.jp)
}

Keywords : GaN, high-output-power, blue, laser diodes

Since the first demonstration of GaN-based laser diodes (LDs) at $405 \mathrm{~nm}$, we have been developping wider wavelength range LDs. At this time, $365 \mathrm{~nm}$ to $482 \mathrm{~nm}$ LDs were realized by using free standing GaN substrate, and improving of the epitaxial growth technology. And these frontier wavelength band LDs have been expanding the possibility of new applications; for example, sensing devices, biotechnology, photolithgraphy, and printing.

And now, full-color display systems using laser light sources are attracting attention for wide-color-gamut applications. In three-prime-colors, red and green high-power and reliable laser light sources are realized by using AlInGaP LDs and second harmonic generation ( $\mathrm{SHG}$ ) lasers, respectively. On the other hand, in blue region, we have proposed GaN-based blue LDs with an emission wavelength of $445 \mathrm{~nm}$. However, high-output-power blue LDs are required because display screen size is becoming larger and larger. Consequently, we developped high-output -power blue LDs with an output power of $500 \mathrm{~mW}$. The details of these LDs characteristics are described.

Figure 1 shows the typical current-voltage (I-V) characteristics and the optical output power per facet of the LD with an emission wavelength of $445 \mathrm{~nm}$ as a function of dc current (L-I) at $25 \mathrm{deg}$. The threshold current density was $1.8 \mathrm{kA} / \mathrm{cm}^{2}$ and the operating current, voltage, and wall-plug efficiency at an output power of $500 \mathrm{~mW}$ were $480 \mathrm{~mA}, 4.8 \mathrm{~V}$, and $21.7 \%$, respectively.

Figure 2 shows the result of lifetime test of CW-operated $445 \mathrm{~nm}$ LDs at a case tempaerature of $25 \mathrm{deg}$ under automatic current control (ACC) with an output power of $500 \mathrm{~mW}$. The lifetime is defined as the time the output power of the LDs declined to 0.5 times the initial output power. After 5000 hours, the lifetime was estimated to be over 30,000 hours.

In this work, we succeeded in fabricating GaN-based highoutput-power $(500 \mathrm{~mW})$ blue LDs with high wall-plug efficiency $(21.7 \%)$ and long lifetime (>30,000 hours). In full-color laser display systems, high-output-power and reliable laser light souces are essential and we believe that our LDs are the enabler for full-color display systems.

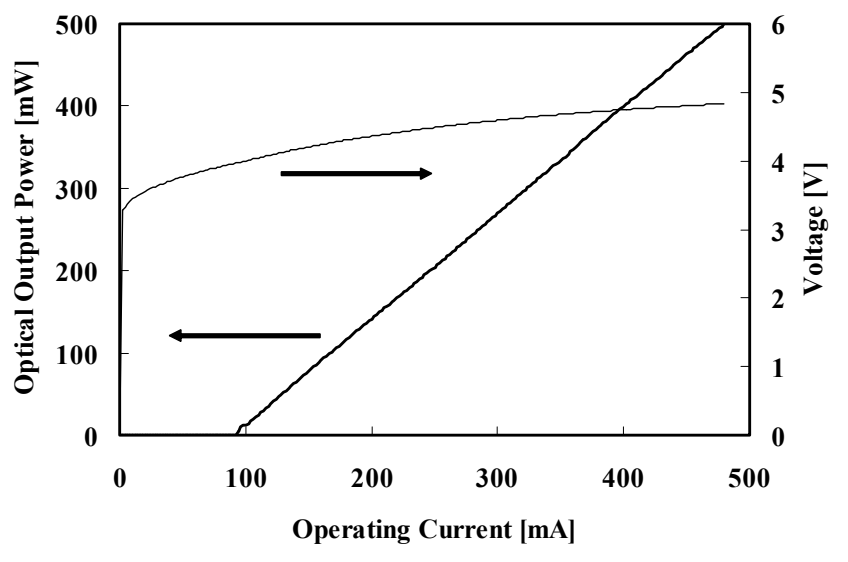

Fig. 1. Typical L-I and V-I characteristics of LDs with a lasing wavelength of $445 \mathrm{~nm}$ under $25^{\circ} \mathrm{C} \mathrm{CW}$ operation

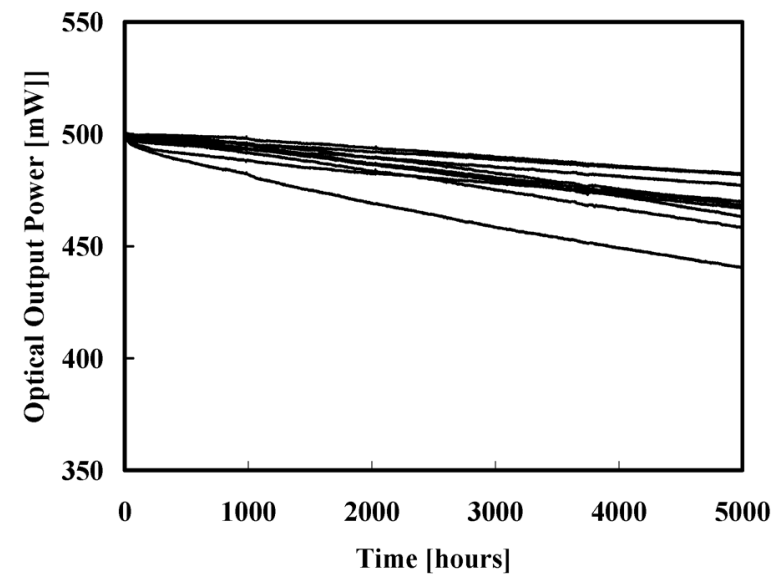

Fig. 2. Result of lifetime test under ACC condition with an output power of $500 \mathrm{~mW}$ at $25^{\circ} \mathrm{C}$ 


\section{$\mathrm{GaN}$ 系高出力青色半導体レーザ}

$\begin{array}{cccccc}\text { 非会員 } & \text { 三好 } & \text { 隆* } & \text { 非会員 } & \text { 小崎 } & \text { 徳也* } \\ \text { 非会員 } & \text { 柳本 } & \text { 友弥* } & \text { 非会員 } & \text { 藤村 } & \text { 康史* } \\ \text { 非会員 } & \text { 長濱 } & \text { 慎一* } & \text { 正 員 } & \text { 向井 } & \text { 孝志* }\end{array}$

GaN-Based High-Output-Power Blue Laser Diodes

Takashi Miyoshi*, Non-member, Tokuya Kozaki*, Non-member, Tomoya Yanamoto*, Non-member, Yasushi Fujimura*, Non-member, Shin-ichi Nagahama*, Non-member, Takashi Mukai*, Member

We succeeded fabricating high-output-power blue $(445 \mathrm{~nm})$ laser diodes (LDs) with an output power of 500mW. The operating current, voltage, wall-plug efficiency of these LDs were $480 \mathrm{~mA}, 4.8 \mathrm{~V}$, and $21.7 \%$. Estimated lifetime of these LDs was over 30,000 hours under continuous wave operation at $25^{\circ} \mathrm{C}$.

キーワード: $\mathrm{GaN}$, 高出力, 青色, 半導体レーザ

Keywords : GaN, high-output-power, blue, laser diodes

\section{1. はじめに}

青紫色 (405nm 帯) GaN 系半導体レーザは近年, HD-DVD, Blue-ray Disc などの高密度光ストレージ用光源として活発 な開発が行われている。我々は 1995 年に初めて $\mathrm{GaN}$ 系材料 でのレーザ発振を達成 ${ }^{(1)} し て 以$ 来, 基板の転位密度低減, 素 子構造の最適化などによって $405 \mathrm{~nm}$ 帯レーザの高出力化を 行い, 光出力 $200 \mathrm{~mW}$ を超えるレーザの開発に成功してい る。

また我々は $405 \mathrm{~nm}$ 帯の高出力化だけではなく, GaN 系レ 一ザの発振波長の広帯域化を行い，現在までに 365 482nm までの波長帯で $\mathrm{CW}$ 発振を実現している(2)(3)。これにより GaN 系レーザはストレージ分野だけではなくバイオ, 印刷, 露光といった様々な分野へアプリケーションを広げてい る。その中でも特に注目するのは青色 (445nm 帯) 半導体 レーザである。青色半導体レーザは現在, レーザディスプ レイ用の光源として大きな注目を集めている。レーザディ スプレイとはRGB 3 種類のレーザを光源に用いたプロジェ クション方式のディスプレイ(4)であり, 従来のディスプレイ では表現が不可能だった領域まで色再現性が広がるという 特徴がある。RGB のうち, 赤色は AlGaInP 系半導体レーザ, 緑色はSHG（Second Harmonic Generation）レーザにより実 現されており，我々は青色光源として GaN 系材料を用いた 青色半導体レーザを提案している。また近年のスクリーン

* 日亜化学工業株式会社

T774-8601 徳島県阿南市上中町岡 491

Nichia Corporation,

491 Oka, Kaminaka-cho, Anan, Tokushima 774-8601
サイズの大型化に伴い, 光源の高出力化が要求されている。 そこで我々は高出力化に向けた開発を行い, 光出力 $500 \mathrm{~mW}$ の青色半導体レーザの作製に成功した。

\section{2. 青色半導体レーザ}

〈2.1〉 青色半導体レーザの特徵 一般に $\mathrm{GaN}$ 系レー ザにおいて長波長化で発振させるためには活性層として用 いられるInGaN の In 組成を上げていく必要があるが，これ によって InGaN 特有の現象である In 組成の空間的摇ら ぎ(5)(6)が大きくなり, 内部損失が増加する。また同時に発振 波長が長波長化するのに伴い, 屈折率の波長分散関係から 活性層とクラッド層との間の屈折率差が減少し, エピ成長 方向の光閉じ込めが低下寸る。これらの結果, 図 1 のよう に 2001 年の段階では発振波長の長波長化に伴って闇值電流 密度が上昇し, $450 \mathrm{~nm}$ 以上の波長での $\mathrm{CW}$ 発振が不可能で あった。

そこで我々はこれらの䦭值電流密度上昇要因に対して, 主に基板転位密度の低減化, InGaN 活性層の結晶性を向上 させる結晶成長技術及びレーザエピ構造の最適化を行っ た。その結果現在では $482 \mathrm{~nm}$ までの長波長化が可能となっ ている。また特記すべきは図 1 の 2006 年時点でのデータに おいて $460 \mathrm{~nm}$ の領域まで䦨值電流密度の上昇がみられてい ないことである。このことは青色領域の発光効率が $\mathrm{GaN}$ 系 LD で最も効率のよいとされる $405 \mathrm{~nm}$ 帯のそれとほぼ同じ であり, 高出力化に関しても十分ポテンシャルがあること を示している。

$\langle 2 \cdot 2\rangle$ 青色半導体レーザの作製・構造 青色半導体 


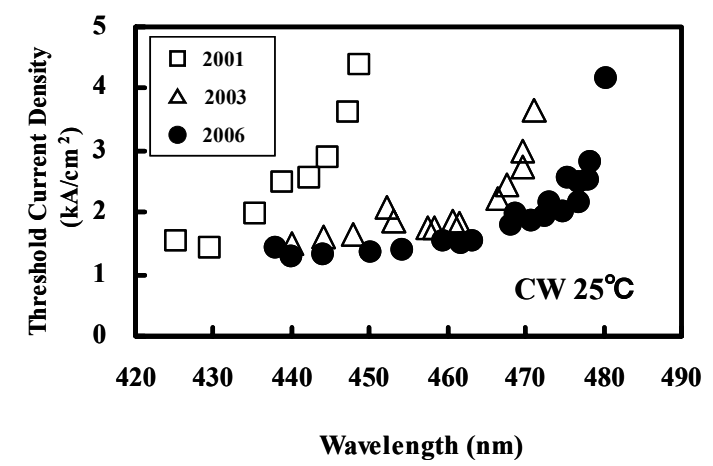

Fig. 1. Wavelength dependence of threshold current density of GaN-based LDs.

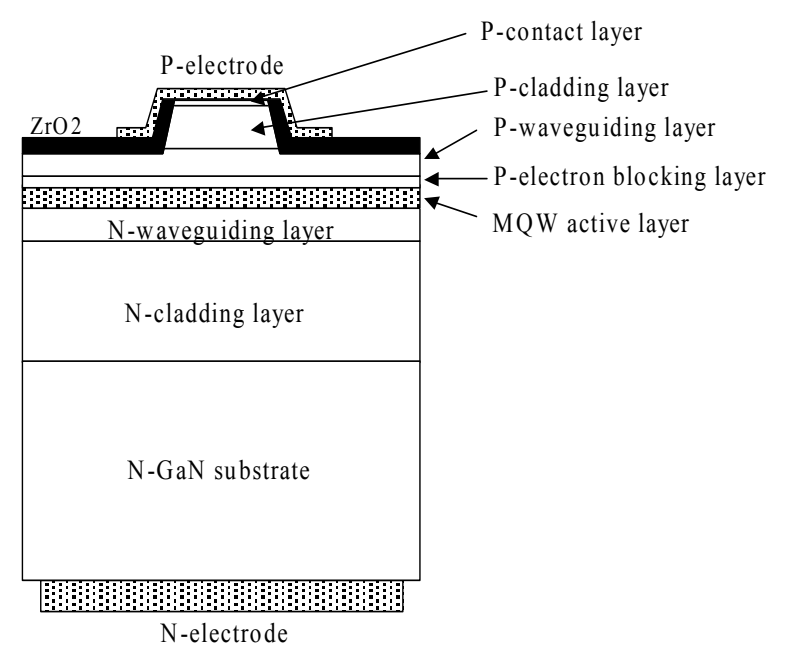

Fig. 2. Schematic structure of blue LDs.

レーザは MOCVD 法を用いて $\mathrm{n}$ 型自立 $\mathrm{GaN}$ 基板(7)(8) 上に工 ピタキシャル成長させた。図 2 に青色半導体レーザの構造 概念図を示す。構造としてはリッジ型導波路を採用し, $\mathrm{ZrO}_{2}$ を埋め込み材料とした。共振器長は $800 \mu \mathrm{m}$ である。ストラ イプ幅については主に高出力化による端面光密度及び駆動 電流密度の上昇を低減寸るため, 一般にシングルモードレ 一ザで用いられている幅 $(2 \mu \mathrm{m}$ 以下) よりも大幅に拡大し, $7 \mu \mathrm{m}$ とした。エピタキシャル構造については前述の LD 波 長の長波長化に伴う成長方向の光閉じ込め係数が低下する ことを防ぐため, 光ガイド層は $\mathrm{InGaN}+\mathrm{GaN}$ の 2 層に, また クラッド層は $\mathrm{Al}$ 組成比を高めた $\mathrm{AlGaN} / \mathrm{GaN}$ 超格子構造を 採用した。活性層は InGaN-MQW（Multi Quantum Well）構 造である。またレーザ端面はへきかいにより作製した後, リア端面には高反射率コーティング（反射率：95\%）を施し， 効率の向上を図った。

$\langle 2 \cdot 3\rangle$ 特 性 図 3 に作製した青色半導体レーザ の電流-電圧（V-I）特性及び電流-光出力（L-I）特性を示す。 閾値電流密度は $1.8 \mathrm{kA} / \mathrm{cm}^{2}$ であり, 光出力 $500 \mathrm{~mW}$ 時の駆動 電流，駆動電圧はそれぞれ $480 \mathrm{~mA} ， 4.8 \mathrm{~V}$ ，これより見積も

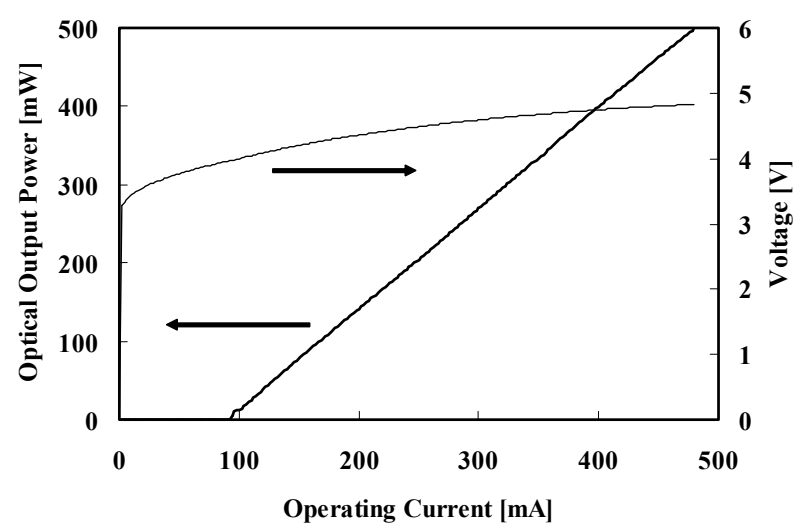

Fig. 3. Typical L-I and V-I characteristics of LDs with a lasing wavelength of $445 \mathrm{~nm}$ under $25^{\circ} \mathrm{C} \mathrm{CW}$ operation.

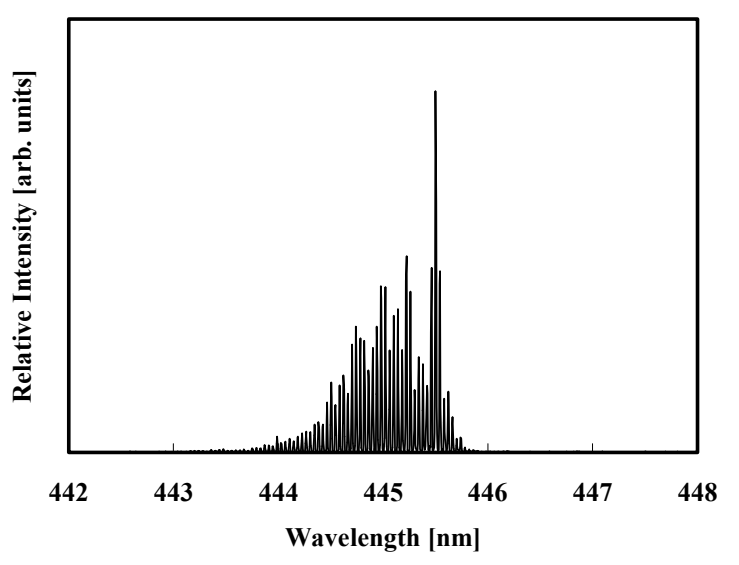

Fig. 4. Emission spectrum of the blue LD measured at an output power of $500 \mathrm{~mW}$ under $25^{\circ} \mathrm{C} \mathrm{CW}$ operation.

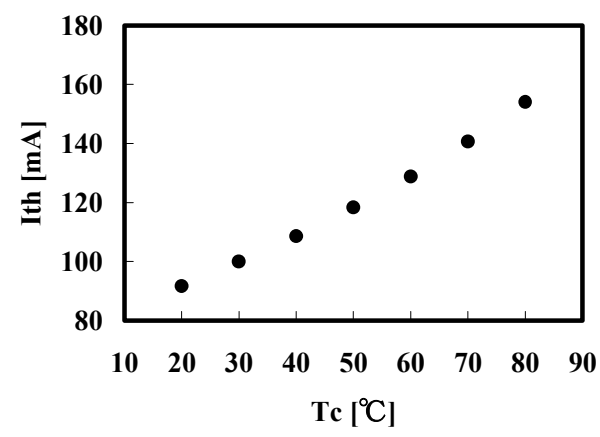

Fig. 5. Temperature dependence of Ith.

られる電力変換効率は $21.7 \%$ あっった。また図 4 に光出力 $500 \mathrm{~mW}$ 時の典型的な発振スペクトルを示す。 $445 \mathrm{~nm}$ 付近に 複数のピークが観測されており, 縦モードはマルチモード であることがわかる。

次に作製した青色半導体レーザの閾值電流の温度依存性 を図 5 に示す。これよりケース温度 $80^{\circ} \mathrm{C}$ こおいても急速な 閾值電流の上昇は無く, 活性層への注入キャリアの閉じ込 


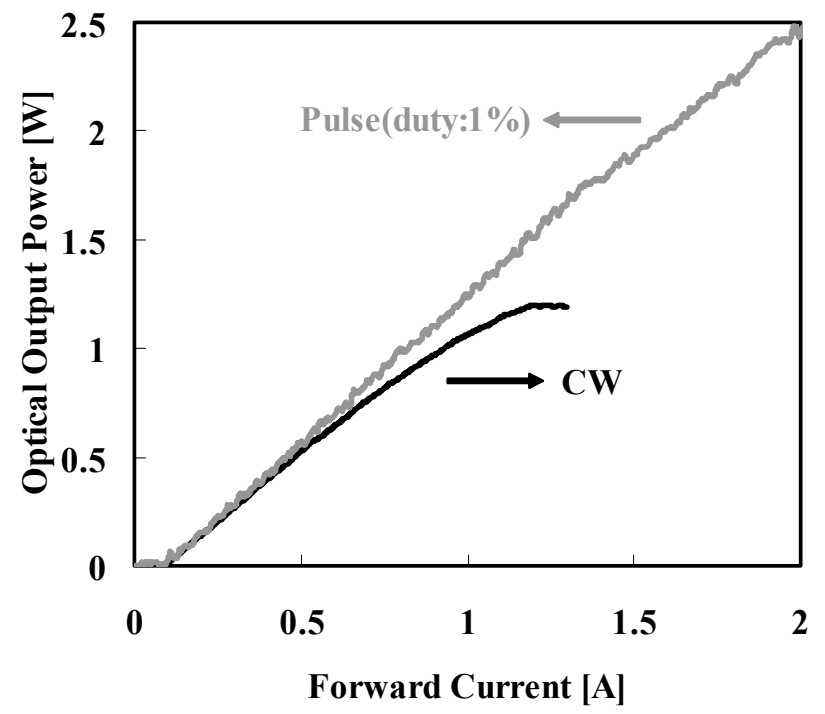

Fig. 6. CW and pulse L-I characteristics of the blue LD with a lasing wavelength of $445 \mathrm{~nm}$ under $25^{\circ} \mathrm{C}$.

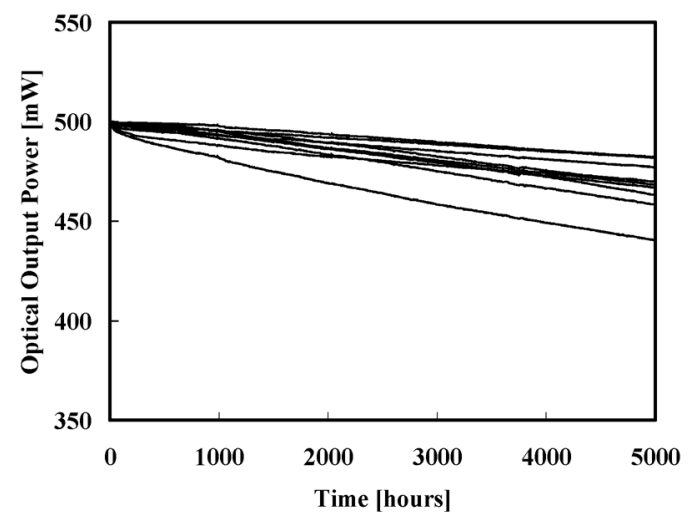

Fig. 7. Result of lifetime test under ACC condition with an output power of $500 \mathrm{~mW}$ at $25^{\circ} \mathrm{C}$.

めが十分であることがわかる。これより見積もられる特性 温度（To）は $127 \mathrm{~K}$ であった。

図 6 は CW 及びパルス駆動（パルス幅: $2 \mu \mathrm{s}$, デューテ イー比：1\%）時の L-I 特性を示している。CW 駆動の場合 光出力が $1.2 \mathrm{~W}$ 程度で飽和しており, 発熱による発光効率の 低下が確認される。なお図 5 のようにケース温度 $80^{\circ} \mathrm{C}$ 程度 までは急速な効率の低下が発生していないことを考慮する と, 飽和状態の温度はそれ以上の高温であると推測される。 一方パルス駆動の場合, 発熱の影響がほとんど無視できる ため光出力 $2.5 \mathrm{~W}$ まで駆動することが可能であった。このこ とは今回作製した青色半導体レーザの光学損傷 (Catastrophic Optical Damage；COD）等の破壊レベルが非常 に高いことを示しており，GaN 系材料の堅牢さを実証する 結果であると考えられる。なお今回 LD 素子を実装したパッ ケージは熱容量が小さく, 熱抵抗が比較的高い汎用ステム （ 5 5.6mmCAN ステム）である。従って更なる高出力化に関
しては, 低熱抵抗のパッケージを使用することによって比 較的容易に達成可能であると考えられる。

次にディスプレイ用光源として使用する場合に重要とな る寿命試験の結果について示す。ディスプレイ用光源とし て要求される寿命は一般に数万時間といわれており, 非常 に高い信頼性が要求される。図 7 はケース温度を $25^{\circ} \mathrm{C}$ に固 定した状態でそれぞれの素子が初期光出力 $500 \mathrm{~mW}$ となる ように電流值を調整し, 定電流制御（ACC）駆動した場合 の光出力の推移を示している。5000 時間まで評価を行った が, すべての試料で突発的な劣化はみられておらず, 安定 性が高いことがわかる。この場合の寿命を出力の半減期 (一 定電流で駆動し, 光出力が初期の 0.5 倍になる期間) で定義 した場合, 5000 時間経過時点での光出力の劣化係数 $(\delta \mathrm{L} /$ $\delta \mathrm{T} ）$ から, 平均寿命は 30,000 時間以上と見積もられた。

\section{3. まとめ}

今回我々はエピ及び導波路構造の改良を行い, 光出力 $500 \mathrm{~mW}$ の $\mathrm{GaN}$ 系高出力青色半導体レーザの開発, 作製に成 功した。作製したレーザは高い電力変換効率 (21.7\%) を持 ち, かつ $2.5 \mathrm{~W}$ まで光学的耐性があることを確認した。また 5000 時間の実駆動試験から寿命は 30,000 時間以上であると 推定され, 非常に要求が厳しいディスプレイ用光源として の特性を満足するものであった。

(平成 19 年 10 月 31 日受付, 平成 19 年 12 月 4 日再受付)

\section{文献}

(1) S. Nakamura, M. Senoh, S. Nagahama, N. Iwasa, T. Yamada, T. Matsushita, H. Kiyoku, and Y. Sugimoto : "InGaN-based multi-quantumwell-structure laser diodes”, Jpn. J. Appl. Phys., Vol.35, pp.L74-L76 (1996)

(2) S. Masui, Y. Matsuyama, T. Yanamoto, T. Kozaki, S. Nagahama, and T. Mukai : "365nm ultraviolet laser diodes composed of quarternary AlInGaN alloy”, Jpn. J. Appl. Phys., Vol.42, pp.L1318-L1320 (2003)

( 3 ) S. Nagahama, Y. Sugimoto, T. Kozaki, and T. Mukai : "Recent progress of AlInGaN laser diodes", Proc. of SPIE, Vol.5738, pp.57-62 (2005)

(4) T. Mizushima, H. Furuya, K. Mizuuchi, T. Yokoyama, A. Morikawa, K. Kasazumi, T. Itoh, A. Kurozuka, K. Yamamoto, and S. Kadowaki : "Laser projection display with low electric consumption and wide color gamut by using efficient green SHG laser and new illumination optics", SID 2006 Digest, pp.1681-1684 (2006)

(5) Y. Narukawa, Y. Kawakami, M. Funato, S. Fujita, S. Fujita, and S. Nakamura : "Role of self-formed InGaN quantum dots for exciton localization in the purple laser diode emitting at $420 \mathrm{~nm}$ ", APL, Vol.70, pp.981-983 (1997)

(6) S. Chichibu, K. Wada, and S. Nakamura : "Spatially resolved cathodoluminescence spectra of InGaN quantum wells", APL, Vol.71, pp.2346-2348 (1997)

( 7 ) S. Nagahama, N. Iwasa, M. Senoh, T. Matsushita, Y. Sugimoto, H. Kiyoku, T. Kozaki, M. Sano, H. Matsumura, H. Umemoto, K. Chocho, and T. Mukai : "High-power and long-lifetime InGaN multi-quantum-well laser diodes grown on low-dislocation-density GaN substrates", Jpn. J. Appl. Phys., Vol.39, pp.L647-L650 (2000)

( 8 ) K. Motoki, T. Okahisa, N. Matsumoto, M. Matsushima, H. Kimura, H. Kasai, K. Takemoto, K. Uematsu, T. Hirano, M. Nakayama, S. Nakahata, M. Ueno, D. Hara, Y. Kumagai, A. Koukitu, and H. Seki : "Preparation of large freestanding $\mathrm{GaN}$ substrates by hydride vapor phase epitaxy using GaAs as a starting substrate", Jpn. J. Appl. Phys., Vol.40, pp.L140-L143 (2001) 


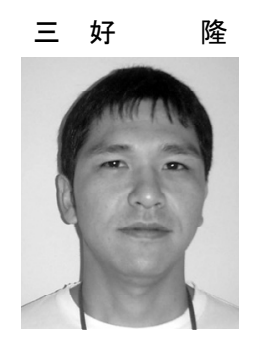

小 崎 徳 也

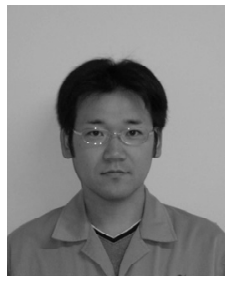

柳 本 友 弥

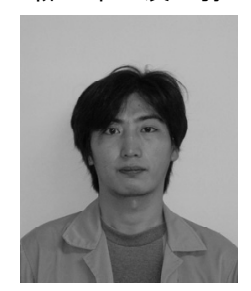

(非会員) 2000 年大阪市立大学大学院工学研究 科前期博士課程修了。同年, 日亜化学工業（株） 入社。現在同社開発部において $\mathrm{GaN}$ 系半導体 レーザの研究開発に従事。専門は $\mathrm{GaN}$ 系半導 体レーザ。

（非会員）1995 年徳島大学大学院工学研究科前 期博士課程修了。同年, 日亜化学工業（株）入 社。現在同社開発部において $\mathrm{GaN}$ 系半導体レ ーザの研究開発に従事。専門は $\mathrm{GaN}$ 系半導体 レーザ。

（非会員）1996 年東京理科大学理工学研究科前 期博士課程修了。同年, 日亜化学工業（株）入 社。現在同社開発部において $\mathrm{GaN}$ 系半導体レ 一ザの研究開発に従事。専門は $\mathrm{GaN}$ 系半導体 レーザ。
藤 村 康 史 (非会員) 2002 年徳島大学大学院工学研究科前

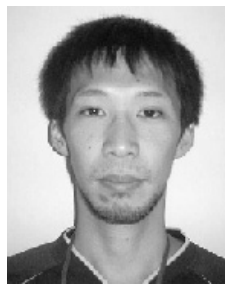
期博士課程修了。同年, 日亜化学工業（株）入 社。現在同社開発部において $\mathrm{GaN}$ 系半導体レ 一ザの研究開発に従事。専門は $\mathrm{GaN}$ 系半導体 レーザ。

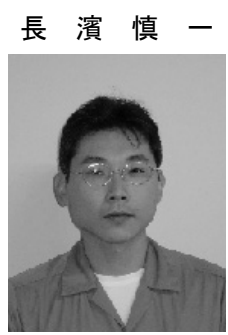

(非会員) 1991 年徳島大学工学部電気工学科卒 業。同年, 日亜化学工業 (株) 入社。同社開発 部において $\mathrm{GaN}$ 系半導体レーザの研究開発に 従事。2002 年, 徳島大学より, 博士号 (工学) を受ける。専門は $\mathrm{GaN}$ 系半導体レーザ。

向 井 孝 志 (正員) 1987 年徳島大学工学部電子工学科卒

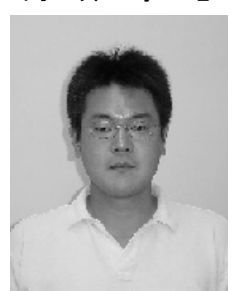
業。同年, 日亜化学工業 (株) 入社。同社開発 部において $\mathrm{GaAs}, \mathrm{GaN}$ 系発光デバイスの研究 開発に従事。2000 年, 徳島大学より, 博士号 (工 学) を受ける。現在, 日亜化学工業窒化物半導 体研究所所長。 